\title{
Comparative accuracy of floor area, storey enclosure and cubic methods in preparing preliminary estimate in Nigeria
}

Received (in revised form): 28th February 2011

\begin{abstract}
Emmanuel Olusegun Akinsiku
is a lecturer in the Department of Building (Quantity Surveying Unit), University of Lagos, Akoka,Yaba, Lagos, Nigeria. He obtained his National Diploma (ND) and Higher National Diploma (HND) in Building Technology from the Federal Polytechnic, Ado Ekiti. He also obtained a BSc degree in Quantity Surveying from the Federal University of Technology, Akure, and and an MSc degree in Construction Management from the University of Lagos, Nigeria. He worked in a Quantity Surveying consultancy firm for a number of years, from where he acquired vast knowledge in construction and project management.
\end{abstract}

\section{Solomon Olusola Babatunde}

is a member of the Nigerian Institute of Quantity Surveyors. He obtained his ND and HND in Quantity Surveying from the Osun State College of Technology, Esa-Oke. He also obtained a BSc degree in Quantity Surveying from the Federal University of Technology, Akure. He started a teaching career at the Department of Quantity Surveying, Osun State College of Technology, Esa-Oke, Nigeria, and is currently working as a lecturer in the Department of Quantity Surveying, Obafemi Awolowo University, Ile-Ife, Nigeria.

\begin{abstract}
Akintayo Opawole
obtained his ND in Quantity Surveying from the Federal Polytechnic, Ede, Nigeria. He also obtained a BSc degree in Quantity Surveying from the Federal University of Technology, Akure, Nigeria, from where he graduated with a first class. He started his teaching career as Assistant Lecturer in the Department of Quantity Surveying, Osun State Polytechnic, Iree, Nigeria. He was a part-time lecturer at the Department of Quantity Surveying, Federal Polytechnic, Ede, Nigeria, in 2007, and is currently working as a lecturer in the Department of Quantity Surveying.
\end{abstract}

Correspondence: Solomon Olusola Babatunde, Department of Quantity Surveying, Obafemi Awolowo University, Ile-Ife, Nigeria E-mail: sholly_intl@yahoo.com

ABSTRACT The aim of construction cost forecasting is to provide an estimate of a construction contract. Construction clients are interested in knowing their financial commitment before the completion of a detailed design. There are various methods used by estimators to forecast the construction cost of building and civil engineering projects. The accuracy of these techniques is, however, impeded by some external factors that need to be overcome or are provided for in order to get a realistic estimated value. This study examined the three most common techniques used in preparing preliminary estimates in Nigeria, namely, the floor area or superficial method, the cubic method and the storey enclosure method. Total construction costs were extracted from the final accounts of 10 bank projects executed within the last 15 months in Lagos metropolis, Nigeria. From the extracted costs, using a random selection, a project was used as the base on which other techniques were used. The data were analysed using their respective deviation from the final cost and the Pearson correlation coefficient was used to test their degree of relationship with the final cost. The study revealed the cubic method of calculating preliminary estimates as having the highest frequency of 
accuracy closest to the obtained construction value with respect to the 10 projects sampled, whereas the floor area and storey enclosure methods followed behind. However, using the Pearson product moment correlation coefficient, the floor area or superficial method has the greatest relationship to the construction cost; the cubic method came second, whereas the storey enclosure method has the least relationship with the construction cost.

Journal of Building Appraisal (2011) 6, 315-322. doi:10.1057/jba.2011.9

Keywords: accuracy; preliminary estimates; construction cost; building

\section{INTRODUCTION}

Accurate preliminary cost estimates for engineering construction and building projects are extremely important for the financier. The primary function of this process is to produce a forecast of the probable cost of a proposed project before the detailed design and contract particulars are prepared (Skitmore, 1988). Prospective clients require a budget estimate at the early stage of the project to manage and forecast their intended financial commitment, as this gives the client a view of his financial commitment before extensive work on the design is done. A preliminary estimate is therefore an important document that helps the client in carrying out a detailed study on the viability of his proposed project with a view to determining whether the investment is worthwhile. Once an initial budget has been established, it is important to test its assumptions by using a series of increasingly precise cost estimating techniques that coincide with further development of design and construction details. The estimates should be provided by a professional estimating firm, either as part of the design team or directly for the owner (Brandon, 1978). However, lack of theories on construction price forecasting is a major factor that has restricted empirical progress in price forecasting (Gunner and Skitmore, 1999).

Estimate of construction works should be prepared at the initial design stage of the project. As more information is obtained about site conditions and proposed solutions, cost estimates typically become more precise and more detailed. Ferry and Brandon (1991) summarized the origins of construction costs into two basic sources, namely, the owner-designer, through the owner's requirements and the design; and the contractors and subcontractors, through the competitive market and their own organizations. Clients are the primary originators of construction costs through their requirements and their ability to pay for them. Although it is possible that some owners may not have precise knowledge of their requirements, they will probably have a clear idea of their financial limitations or be curious to know the cost of a particular design that they have conceived. Estimation of construction cost involves the determination of the cost of doing the work. This is not limited to the knowledge of costs of labour, material, equipment and other direct costs of doing the work. It is also dependent on the interplay of the design variables (morphology) and the estimator's choice of alternative means of construction and methods of doing the work (Ibrahim, 2003).

\section{Classes of estimates}

Several scholars have identified various classes of estimates on the basis of their perception of its importance. Skitmore (1990) identified three basic types of estimates. These include approximate estimates (or rough, or pre-design estimates), which are generally applied to assess the magnitude of a project before its design. It can also be 
performed with minimum preparation of design and related information. Therefore, it is based on a sound intelligent guess, judgement and experience of similar projects. The second class is a preliminary or definitive estimate, which is used for accessing the relative costs of alternative designs or comparing alternative schemes in economic studies. It requires design and preparation of drawings. When more details and a reasonable quantity can be obtained, the accuracy can possibly be lowered. The third classification is the detailed estimate, which provides the final assessment of the cost of a project and is compiled from drawings, specifications and bill of quantities.

Seeley (1996), however, classified estimating methods into single-purpose estimates, dual-purpose estimates, single-purpose preliminary estimates, single-purpose later-stage estimates, primary conservative cost estimates and secondary conservative cost estimates. All the above classifications are geared towards giving the client a clear view of his intended financial commitment in executing a construction project. These methods can be used in various stages of the design process, depending on the amount of information available to the estimator, which invariably has effects on the accuracy of his estimates.

\section{Estimating techniques used at the pre-design stage}

The Association for the Advancement of Cost Engineering defined cost estimate as a compilation of all the costs of the elements of a project or efforts included within an agreed-upon scope. Collier (1987) defined a construction cost estimate as the best judgement of what a project will eventually cost. As an estimate is prepared before the commencement of work, its accuracy will depend on the skill and judgement of the estimator. Raddon (1982) defined skill as the 'accurate use of proper estimating methods', and judgement as the 'correct visualization of the work as it will be carried out'. In view of this, estimating is a key to a successfully conceived, managed and completed project.

Ibrahim (2003) stressed that an estimate contains three interdependent variables: (i) quantity, (ii) quality and (iii) cost. These three variables are functions of construction documentation, which are drawings and specifications. It dictates the quantity and quality of materials required, and cost is determined on the basis of these two elements. If a specific cost or budget is to be maintained, either the quantity or quality of the components is adjusted to meet the cost requirement. The primary function of any cost estimate is to produce a forecast of the probable cost of a future project. In this way the client is made aware of his likely financial commitments before extensive design work is undertaken, to determine the feasibility of the project or funding requirements. This will ensure the most economical choice from a list of alternative design proposals, and the control of project costs during the design phase.

Generally, pre-design estimates serve as both budgetary and planning tools. They are used for different reasons and are therefore made using different methods, with each method providing different answers. The choice of method to be used is usually dictated or influenced by the purpose of the estimate, the amount of information available and/or required by the system, the time available for making the estimate and the experience of the estimator. The preparation of accurate early cost estimates is very important to both the sponsoring organization and the project team. For the sponsoring organization, Oberlender and Trost (2001) stressed that early cost estimates are vital for business unit decisions that include strategies for asset development, potential project screening and resource commitment for further project development. For the project team, the performance and overall project success are often measured by how well the actual cost compares to the early cost estimates. Although there are no universally accepted names 
for the different types of pre-design cost estimates, most estimators will agree that each type has its place in the estimation of construction cost. The type of estimate used is related to the amount of design information available. As the project proceeds through the different phases of design, the type of estimate changes and the accuracy of the estimate also increases.

The common estimating techniques for construction projects are the functional unit method, the floor area unit method, the cubic method, the storey enclosure method and cost modelling. The functional unit method is used when the estimator has enough historical data available from experience on a particular type of project to relate some end-product units to construction costs. This allows an estimate to be prepared for a similar project when the only major difference between the projects is their size. Seeley (1996) commented that the weaknesses of this method lie in its lack of precision, in the difficulty in making allowance for a whole range of factors such as the shape and size of the building, form of construction, materials and finishings among others, and the low accuracy for the majority of purposes. The use of this technique is limited to public projects and/or to very early stages of project definition, where very little design has been undertaken. The floor area unit method is the most commonly used unit-cost estimate. The method involves measuring the total floor area of all storeys between external walls without deductions for items such as internal walls, lifts and stairwells among others. By multiplying the historical square-metre cost by the calculated square metre of floor area for the proposed building, a pre-construction preliminary cost estimate for the building can be determined. The major weakness of this method is the imprecision in making allowances for plan shape, storey height, number of floors and changes in specification. Further, separate allowance must be made for site work and external services.

The cubic method of estimate relates the cost of a building to its volume. Cost-percubic-metre estimates are rather unreliable unless virtually identical buildings are compared, as there does not exist a significant relationship between the volume of a building and its cost. The primary weakness of this method is its deceptive simplicity. It is quite a simple operation to calculate the volume of a building, but the difficulty lies in the incorporation of the several design factors into the cubic unit-rate. This method fails to make allowance for plan shape, storey height and number of storeys, and for column spacing, all of which influence cost; moreover, cost variations arising from differences such as alternative foundation types are difficult to incorporate in single unit rate (Seeley, 1996).

The storey enclosure method is based on the area of all the horizontal and vertical planes of the building. The principal objective of this method is to devise an estimating system, which, although leaving the type of structure and standard of finishings to be assessed in the price rate, would take into account building shape, total floor area, vertical positioning of floor areas in the building, storey height of buildings and extra cost of sinking usable floor area below ground level. The method has had little application in industry because of the volume of work involved and the dearth of published cost data for its application.

Cost models are mathematical formulae used for forecasting the estimated cost of proposed construction projects (Ashworth, 1994). A model is built from currently available data and from factors related to previous performance. This information is analysed in model form so that the trends can be correlated from which predictions can then be made about the future.

The approximate estimate method is also likened to preparing a rough estimate for the project based on available data. The pricing method is like that of an abbreviated bill of 
quantities, which provides excellent checking during the design stage of a project. The method reflects the adjustment of quality and quantity. Its major weakness is that it is a time-consuming process and can be applied only in later stages of construction planning when there is a detailed design.

The elemental cost analysis method uses elemental cost analyses of previous projects as a basis for the estimate. The cost is on a superficial basis but the superficial unit cost is broken down into elements and sub-elements, which allows for cost adjustment of variations in the design of the new project compared with the previous scheme. The method is flexible, easily understood by all parties, facilitates comparison between projects and facilitates analysis of cost implications of design decisions. However, it is a time-consuming process and requires a high level of expertise.

\section{Factors affecting the accuracy of estimates}

Factors affecting the accuracy of estimates are essentially procedural errors, human errors and the uncertain nature of the project. Procedural errors relate to accuracy in pricing, cost involved in pricing, availability of methods of pricing and availability of price data. On the other hand, human errors relate to changes in design and incomplete information, accidental errors caused by procedural mistakes (including omitting items, using wrong dimensions), judgemental errors caused by poor or wrong judgement on the part of the estimator (including overlooking, poor pricing and not allowing wastage) and deliberate errors caused by the estimator. Uncertain nature of the project relates to weather conditions, construction delays, supervision policies, construction methods, political and economic variations, changing nature of construction technology and costs, difference in maintenance technology, differences in labour productivity and materials and equipment availability.

\section{RESEARCH METHODOLOGY}

The population for this research article comprised bank projects that were completed in the last 15 months within Lagos metropolis, Nigeria. In order to maintain consistency, the research samples were narrowed down to bank projects with similar functional and quality requirements. The authors were of the opinion that this would provide a uniform basis in comparing the accuracy of the preliminary estimating methods under consideration. The sample size consisted of 10 total construction costs extracted from the various bill of quantities of the bank projects. The data were obtained by extracting the final construction cost from the final account of sampled construction projects executed within the last 15 months from quantity surveying practising consultancy firms in the study area. The gross floor area and storey height measurements were obtained from the contract drawings of the sampled projects.

The data obtained were analysed using percentage and average techniques. However, in addition to these techniques, standard deviation was used to measure the dispersion of these estimating methods with respect to the value obtained from the final account of each project.

\section{DATA ANALYSIS AND DISCUSSIONS}

Calculations were made to get the preliminary estimated cost using a project as the base project from which historical cost data were obtained to predict the cost of the remaining 10 projects.

Table 1 shows the total construction cost obtained from the final account of completed (10) executed projects within the last 15 months. The table shows a range of \#53158537.56k from the obtained values. It was observed that two projects have three floors (Project 1 and 3), seven projects have two floors, whereas only one project has a 
Table I: Total construction cost

\begin{tabular}{lccc}
\hline & Gross floor area $\left(\mathrm{m}^{2}\right)$ & Construction cost (Naira) & Number offloors \\
\hline Base project & 576 & 33857056.25 & 2 \\
Project I & 1194 & 59689831.79 & 3 \\
Project 2 & 536 & 25965074.00 & 2 \\
Project 3 & 275 & 22441462.44 & 1 \\
Project 4 & 642 & 46496663.18 & 2 \\
Project 5 & 400 & 34682731.14 & 2 \\
Project 6 & 510 & 39457447.44 & 2 \\
Project 7 & 716 & 50305469.25 & 2 \\
Project 8 & 544 & 41535965.89 & 2 \\
Project 9 & 406 & 42628883.75 & 2 \\
Project 10 & 1350 & 75600000.00 & 3 \\
\hline
\end{tabular}

IUS\$=|49 Nigerian Naira; I $€=250$ Nigerian Naira.

Table 2: Comparison of estimated cost with construction cost

\begin{tabular}{|c|c|c|c|c|c|}
\hline & $\begin{array}{c}\text { Construction } \\
\text { cost (Naira) }\end{array}$ & $\begin{array}{l}\text { Floor area } \\
\text { method } \\
\text { (estimate) }\end{array}$ & $\begin{array}{l}\text { Cubic } \\
\text { method } \\
\text { (estimate) }\end{array}$ & $\begin{array}{c}\text { Storey } \\
\text { enclosure method } \\
\text { (estimate) }\end{array}$ & $\begin{array}{l}\text { Number } \\
\text { of floors }\end{array}$ \\
\hline Base project & 33857056.25 & 33857056.25 & 33857056.25 & 33857056.25 & 2 \\
\hline Project I & 59689831.79 & 69830178.52 & 102516645.05 & 65705461.00 & 3 \\
\hline Project 2 & 25965074.00 & 31505871.79 & 32846547.18 & 30384881.94 & 2 \\
\hline Project 3 & $2244 \mid 462.44$ & 32328786.35 & 19947549.02 & 29928370.23 & I \\
\hline Project 4 & 46496993.18 & 37736510.61 & 39342319.57 & 37418742.66 & 2 \\
\hline Project 5 & 34682731.14 & 23511844.62 & 24679099.32 & 25038324.28 & 2 \\
\hline Project 6 & 39457447.44 & 29977601.89 & 31253244.52 & 30653418.23 & 2 \\
\hline Project 7 & 50305469.25 & 42086201.87 & 43877104.07 & 41354589.65 & 2 \\
\hline Project 8 & 41535965.89 & 31976108.68 & 33563575.07 & 33119476.56 & 2 \\
\hline Project 9 & 42628883.75 & 23864522.29 & 27080308.98 & 25038324.28 & 2 \\
\hline Project 10 & 75600000.00 & 79352475.59 & | |4807837.02 & 73874335.14 & 3 \\
\hline
\end{tabular}

IUS\$= I49 Nigerian Naira; I $€=250$ Nigerian Naira.

single floor (Project 3). The table also reveals that the gross floor area is proportional to the construction cost; that is, the more the gross floor area, the higher the construction cost. 'Project 10' has the highest floor area of $1350 \mathrm{~m}^{2}$, followed by 'Project 1 ' of $194 \mathrm{~m}^{2}$, with $\$ 7560000.00 \mathrm{k}$ and $\$ 59689831.79 \mathrm{k}$ of total construction cost, respectively, whereas 'project 3 ' has the lowest floor area of $275 \mathrm{~m}^{2}$ with $\# 22441462.44 \mathrm{k}$ of total construction cost.

Table 2 shows the various estimated costs derived from the use of the three methods of preliminary estimation. The degree of deviation of the results obtainable from the three methods from the actual construction cost is presumed to define the accuracy of the methods and is partly due to external factors that were not considered in estimating the unit cost $/ \mathrm{m}^{2}$. The results from the cubic method have the highest frequency of six projects, with the accuracy closest to the obtained construction value with respect to the 10 projects. Both the floor area and storey enclosure methods have estimates closest to the construction cost on only two occasions each. The results indicate that keeping factors such as inflation, location of site, variations in site conditions, design and specification constant, the cubic method stands out as the most appropriate method for this type of project.

\section{Investigation of the degree of accuracy of floor area, cubic and storey enclosure methods.}

Table 3 shows the accuracy of the three methods used with respect to the final construction cost obtained from the final account of the respective projects. It is observed 
Table 3: Accuracy level of preliminary estimating methods

\begin{tabular}{lccccl}
\hline & $\begin{array}{c}\text { Floor area } \\
\text { method (\%) }\end{array}$ & $\begin{array}{c}\text { Cubic } \\
\text { method (\%) }\end{array}$ & $\begin{array}{c}\text { Storey enclosure } \\
\text { method (\%) }\end{array}$ & $\begin{array}{c}\text { Number of } \\
\text { floors }\end{array}$ & Remark \\
\hline Project I & 16.99 & 71.75 & 10.08 & 3 & Storey Enclosure \\
Project 2 & 15.45 & 20.37 & 17.02 & 2 & Floor area \\
Project 3 & 25.35 & 53.94 & 33.36 & 1 & Floor area \\
Project 4 & 18.84 & 15.39 & 19.52 & 2 & Cubic \\
Project 5 & 30.85 & 27.42 & 27.81 & 2 & Cubic \\
Project 6 & 24.03 & 20.79 & 22.31 & 2 & Cubic \\
Project 7 & 15.87 & 12.29 & 17.79 & 2 & Cubic \\
Project 8 & 20.75 & 16.82 & 20.26 & 2 & Cubic \\
Project 9 & 43.74 & 36.16 & 41.26 & 2 & Cubic \\
Project 10 & 4.96 & 51.86 & 2.28 & 3 & Storey enclosure \\
\hline
\end{tabular}

Table 4: Pearson correlation coefficient

\begin{tabular}{lcc}
\hline Floor area method & Cubic method & Storey enclosure method \\
\hline 0.92 & 0.91 & 0.87 \\
\hline
\end{tabular}

that the cubic method has a percentage of 60 per cent accuracy with respect to the total (10) projects sampled; that is, the cubic method has the lowest percentage deviations from actual total construction cost in 6 out of 10 projects sampled, whereas both floor area and storey enclosure methods have 20 per cent accuracy, respectively, in 2 out of 10 projects sampled.

Table 4 shows the Pearson product moment correlation coefficient of the set of calculated data obtained using the preliminary estimating techniques. It is observed that the floor area method has the strongest relationship of 0.92 in comparison with the cubic method, which has a correlation coefficient of 0.91 , and the storey enclosure method, which has a coefficient of 0.87 .

\section{CONCLUSION}

The research revealed that the cubic method of calculating preliminary estimates has the highest frequency of accuracy closest to the obtained construction value with respect to the 10 projects sampled, whereas both floor area and storey enclosure methods followed behind, with both methods being closest to the construction cost on two occasions each. The study further showed that, using the Pearson product moment correlation coefficient, the floor area method had the greatest relationship to the construction cost with a correlation coefficient of 0.92 , the cubic method came second with a coefficient of 0.91 , whereas the storey enclosure method had the least relationship with construction cost with a coefficient of 0.87 .

However, from the results of this research, it is pertinent to say that when an estimate is to be prepared for a building project with one or two floors the most appropriate method is the floor area method, whereas when the floors range between two and three the most appropriate method is the cubic method. The cubic method takes into consideration the height of the building with respect to the estimate. In instances in which the project involves multiple storeys, the most accurate of these three methods is the storey enclosure method. This is adduced to the fact that storey enclosure assigns weighting values to each floor in order to cater to the additional cost of constructing upper floors. Thus, the storey enclosure method is reliable whenever the project involves multiple floors, the floor area or superficial method is accurate when there are not more than two floors and the cubic 
method is advisable when the floors are between two and three. The accuracy of preliminary estimating methods depends on the skill and expertise of the estimators, the availability of information at the time the estimates are being prepared and the time available for the estimator to prepare the estimate. However, in Nigeria, estimators are in most cases not allowed sufficient time by clients. It is a situation in which designers (architects and engineers) are given not less than 4 weeks to complete their drawings, and clients expect the estimators to complete the preparation of the estimate overnight. This scenario is also presumed to have a significant influence on the reliability and performance of most construction cost estimates. Construction estimators should therefore consider external factors such as inflation, location of site, variations in site conditions, design and specification while preparing estimates. Clients should likewise endeavour to give estimators sufficient time to prepare estimates.

\section{REFERENCES}

Ashworth. (1994) Cost Studies of Buildings. London: Longman.

Brandon, P.S. (1978) A framework for cost exploration and strategic cost planning in design. Chartered Surveyor Building and Quantity Surveying Quarterly 5(4): 60-63.

Collier. (1987) Fundamentals of Constructing Estimating and Cost Accounting. Englewood Cliffs, NJ: Prentice Hall. Ferry and Brandon (1991) Cost Planning of Buildings. London: Granada.

Gunner, J. and Skitmore, R.M. (1999) Comparative analysis of pre-bid forecasting of building prices based on Singapore data. Journal on Construction Management and Economics 6(3): 267-275.

Ibrahim, A.D. (2003) Cost implications of architectural design variables. A Master thesis in Construction Engineering and Management King Fahd University of Petroleum \& Minerals, Saudi Arabia.

Oberlender, G.D. and Trost, S.M. (2001) Predicting accuracy of early cost estimates based on estimate quality. Journal of Construction Engineering and Management 127(3): 173-182.

Raddon, P.S.B. (1982) Building Cost Techniques. London: E. and F.N. Spoon.

Seeley, I.H. (1996) Building Economics. London: Macmillan.

Skitmore, R.M. (1988) Factors affecting accuracy of engineering estimates. Cost Engineering 30(10): 16-23.

Skitmore, R.M. (1990) The Accuracy of Construction Price Forecasts: A Study of Quantity Surveyors' Performance in Early Stage Estimating. Technical Report, Department of Surveying, University of Salford. 